\title{
Rationale and design of the Multicenter Medication Reconciliation Quality Improvement Study (MARQUIS)
}

Amanda H Salanitro ${ }^{1,2^{*}}$, Sunil Kripalani ${ }^{2}$, JoAnne Resnic ${ }^{3}$, Stephanie K Mueller ${ }^{4}$, Tosha B Wetterneck ${ }^{5}$, Katherine Taylor Haynes ${ }^{6}$, Jason Stein ${ }^{7}$, Peter J Kaboli ${ }^{8}$, Stephanie Labonville ${ }^{9}$, Edward Etchells ${ }^{10}$, Daniel J Cobaugh ${ }^{11}$, David Hanson ${ }^{12}$, Jeffrey L Greenwald ${ }^{13}$, Mark V Williams ${ }^{14}$ and Jeffrey L Schnipper ${ }^{15}$

\begin{abstract}
Background: Unresolved medication discrepancies during hospitalization can contribute to adverse drug events, resulting in patient harm. Discrepancies can be reduced by performing medication reconciliation; however, effective implementation of medication reconciliation has proven to be challenging. The goals of the Multi-Center Medication Reconciliation Quality Improvement Study (MARQUIS) are to operationalize best practices for inpatient medication reconciliation, test their effect on potentially harmful unintentional medication discrepancies, and understand barriers and facilitators of successful implementation.

Methods: Six U.S. hospitals are participating in this quality improvement mentored implementation study. Each hospital has collected baseline data on the primary outcome: the number of potentially harmful unintentional medication discrepancies per patient, as determined by a trained on-site pharmacist taking a "gold standard" medication history. With the guidance of their mentors, each site has also begun to implement one or more of 11 best practices to improve medication reconciliation. To understand the effect of the implemented interventions on hospital staff and culture, we are performing mixed methods program evaluation including surveys, interviews, and focus groups of front line staff and hospital leaders.

Discussion: At baseline the number of unintentional medication discrepancies in admission and discharge orders per patient varies by site from 2.35 to 4.67 (mean=3.35). Most discrepancies are due to history errors (mean 2.12 per patient) as opposed to reconciliation errors (mean 1.23 per patient). Potentially harmful medication discrepancies averages 0.45 per patient and varies by site from 0.13 to 0.82 per patient. We discuss several barriers to implementation encountered thus far. In the end, we anticipate that MARQUIS tools and lessons learned have the potential to decrease medication discrepancies and improve patient outcomes.
\end{abstract}

Trial registration: Clinicaltrials.gov identifier NCT01337063

Keywords: Medication reconciliation, Hospitalization, Quality improvement, Care transitions

\footnotetext{
* Correspondence: Amanda.Salanitro@Vanderbilt.Edu

${ }^{1}$ Geriatric Research, Education and Clinical Center, VA Tennessee Valley Healthcare System, Nashville, TN, USA

${ }^{2}$ Section of Hospital Medicine, Division of General Internal Medicine and Public Health, Department of Medicine, Vanderbilt University, Nashville, TN, USA

Full list of author information is available at the end of the article
}

\section{Biomed Central}

(c) 2013 Salanitro et al.; licensee BioMed Central Ltd. This is an Open Access article distributed under the terms of the Creative Commons Attribution License (http://creativecommons.org/licenses/by/2.0), which permits unrestricted use, distribution, and reproduction in any medium, provided the original work is properly cited. 


\section{Background}

One of the most prevalent hazards facing hospitalized patients is unintentional medication discrepancies, i.e. unexplained differences in documented medication regimens across different sites of care [1,2]. Unresolved medication discrepancies can contribute to adverse drug events (ADEs), resulting in patient harm [3,4]. Nearly two-thirds of inpatients have at least one unexplained discrepancy in their admission medication history, and some studies found up to 3 medication discrepancies per patient [5-7]. Such medication discrepancies are either caused by history errors (i.e., errors in determining a patient's preadmission medication list) or reconciliation errors (i.e., errors in orders despite accurate medication histories) [3,4].

One way to minimize medication discrepancies and improve patient safety is to perform high quality medication reconciliation, defined as the process of identifying the most accurate list of all medications a patient is taking and using this list to provide correct medications for patients anywhere within the healthcare system $[8,9]$. Since 2005 The Joint Commission (TJC) has required U.S. hospitals to conduct medication reconciliation on admission, upon transfer, and at discharge [10]. Additionally, the World Health Organization has encouraged all member states to implement medication reconciliation at care transitions [11]. When tested, hospital-based medication reconciliation interventions have consistently demonstrated reductions in medication discrepancies, though effects on more distal outcomes such as readmission have been less consistent and limited by study size $[12,13]$. Yet, one study at two large urban academic hospitals found that general medical inpatients averaged more than one potentially harmful discrepancy in either admission or discharge medication orders despite documented completion of medication reconciliation [14].

Though medication reconciliation practices are required at care transitions throughout hospitalization, implementation has been challenging for many hospitals because it often involves a dramatic change in work processes and additional tasks for busy clinicians. Furthermore, the implementation of medication reconciliation interventions varies widely across hospitals, and hospitals need clearer guidance on which interventions are more likely to be successful in their local environment [15]. Moreover, it has been relatively easy for hospitals to document compliance with medication reconciliation processes to meet national and international standards without demonstrating that medication safety has actually improved. To identify and address the barriers to implementing medication reconciliation, an Agency for Healthcare Research and Quality (AHRQ)-funded conference organized by the Society of Hospital Medicine (SHM) in 2009 brought together 36 key stakeholders from 20 organizations representing healthcare policy, patient safety, regulatory, technology, and consumer and medical professional groups. The conference yielded a White Paper with recommendations, including a call for further research [16]. To address the latter, SHM subsequently received funding from AHRQ to conduct the Multi-Center Medication Reconciliation Quality Improvement Study (MARQUIS; clinicaltrials.gov identifier NCT01337063).

The specific aims of MARQUIS are to:

1. Develop a toolkit consolidating the best practices for medication reconciliation, based on the strongest evidence available.

2. Conduct a multi-site mentored quality improvement (QI) study in which each site adapts the tools for its own environment and implements them.

3. Assess the effects of medication reconciliation QI interventions on unintentional medication discrepancies with potential for patient harm.

4. Conduct rigorous program evaluation to determine the most important components of a medication reconciliation program and how best to implement them.

This paper describes the design and early methodological lessons learned from MARQUIS, an example of real-world, rigorous, mixed methods QI research. It is our hope that the design of the study, rationale for that design, and early experiences will be useful for other medication safety efforts, as well as for QI and patient safety research in general.

\section{Methods}

\section{Conceptual framework}

The MARQUIS conceptual framework is based on Brown and Lilford's model for evaluating patient safety interventions, which is an adaptation of Donabedian's "structure-process-outcome" model [17-21]. The model distinguishes interventions that focus on management processes (e.g., provider training) from those that focus on clinical processes (e.g., tools supporting medication list comparisons across care transitions). MARQUIS involves both types of interventions, focusing primarily on the latter. To better understand why interventions succeed or fail, we assess contextual factors (i.e., micro- and macroorganizational structure and existing management processes) and intervening variables (e.g., team climate, safety culture, and knowledge of medication safety principles, Figure 1). Also important to understanding whether interventions succeed or fail is intervention fidelity, or the faithfulness with which the intervention is performed, which can be influenced by how usable the tools are and the degree of training and support given to front-line 


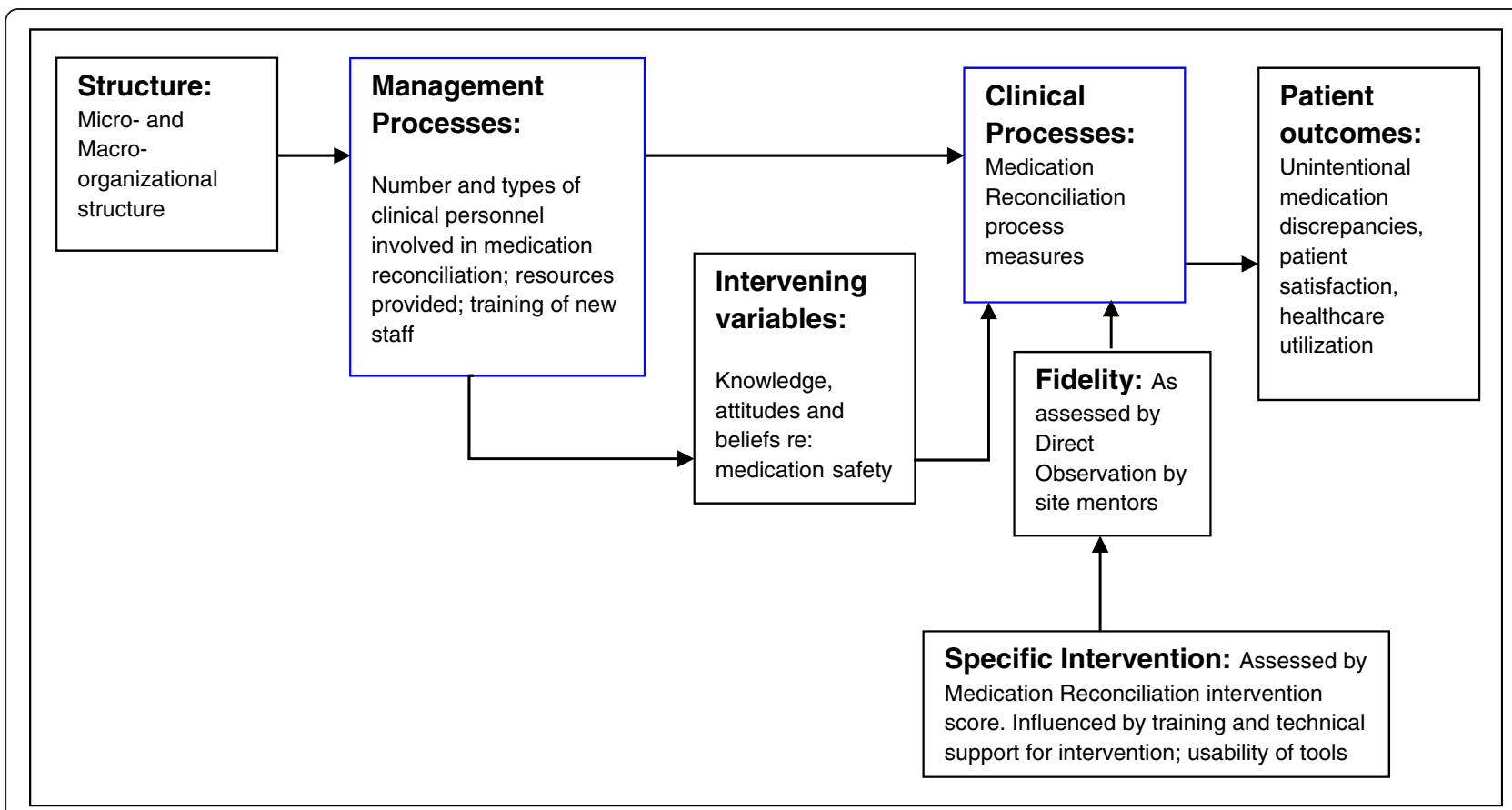

Figure 1 Conceptual framework for MARQUIS.

clinicians (i.e., items at the level of intervention in Figure 1). These are measured as an "intervention score" updated monthly to assess what toolkit components have been adopted and how the state of medication reconciliation changes over time (Table 1). Along with the MARQUIS intervention itself, each of the contextual factors may affect the patient-level outcomes being assessed, such as unintentional medication discrepancies, patient satisfaction, and healthcare utilization (i.e., items to the right of the intervention, Figure 1).

\section{Toolkit}

The MARQUIS toolkit, described elsewhere, [22] synthesizes best practices in medication reconciliation and provides aids to facilitate their implementation. The toolkit components were informed by a systematic review of medication reconciliation interventions, [12] the AHRQ-funded conference of stakeholders,[16] and the work of the MARQUIS investigators and advisory board.

Each toolkit component is framed as a standardized functional goal (e.g., "Improve access to preadmission medication sources"). This approach is ideal for complex QI interventions, [23] allowing sites to: 1) integrate intervention components with their baseline medication reconciliation efforts, information system capabilities, and organizational structures; and 2) add, customize, and iteratively refine the toolkit components and their implementation over time. This approach also improves generalizability, allowing other organizations to apply the lessons learned regardless of their culture or unique circumstances.

While recognizing the importance of flexibility, it was nevertheless important to have some common elements across sites. Thus, each site prioritized the implementation of certain toolkit components based on their potential for improvement and effort required. These included provider education on medication history taking, patient education and teach-back at discharge, patient risk stratification, and more intensive medication reconciliation efforts in highrisk patients.

\section{Study sites}

Six U.S. sites are participating in this study: 3 academic medical centers, 2 community hospitals, and 1 Veterans Affairs hospital. We purposely chose sites that vary in size, academic affiliation, geographic location, and use of health information technology (Table 2). However, all sites had several common features: 1) medication reconciliation was a priority; 2) hospital leadership was committed to making further improvements in the process; 3) an active hospitalist group was engaged in QI; 4) a suitable hospitalist and/or pharmacist clinical champion at each site; and 5) each site planned to use primarily its own resources to pursue this effort.

Patient subjects are drawn from the medical and surgical inpatient, non-critical care units of each site, and are included if hospitalized long enough for a "gold-standard" medication history to be obtained by a study pharmacist (i.e., generally more than 24 hours). Institutional Review 
Table 1 Intervention components and scoring system

\section{Toolkit component}

Definition of Medication

Reconciliation

Assigning roles and responsibilities to clinical personnel

\section{Standardization by function}

Definition exists, is widely disseminated and can be articulated by staff involved in the medication reconciliation process

Roles and responsibilities are well defined for each phase of medication reconciliation and can be articulated by staff involved in the medication reconciliation process; process owner (e.g., attending physician) is well defined and known by those who own the process

Improving access to preadmission medication sources

Encouraging patient-owned medication lists

Educating providers on how to take a best possible medication history

Implementing discharge counseling that includes patient education and teach back

Identifying patients as high vs. low-intermediate risk by stratification
All sites improve exchange of medication information across settings, e.g., community pharmacy prescription information, outpatient medication lists, and inpatient discharge medication orders to all clinical settings

All sites develop (on paper or

electronically) a universal instrument to capture the current medication list, based on steering committee guidelines

Providers receive training in taking a best possible medication history, receive feedback on their skills, and have time to perform it well

Providers counsel patients regarding discharge medications using a standard script that accommodates patients with low health literacy

Sites use established risk factors to identify patients at high risk for medication errors, and patient risk drives the type of intervention received
Implementing intense vs. standard bundle

Implementing and improving electronic medication reconciliation applications where possible

\section{Scoring system for analysis}

0-24 points in 8-point increments, depending on whether definition exists, is widely implemented, and can be articulated by $>80 \%$ of staff involved in the medication reconciliation process

0-12 points in 4-point increments, depending on whether roles are well defined, defined for each phase of the medication reconciliation process, and can be articulated by $>80 \%$ of staff

0-12 points in 4 point increments, depending on whether process owner is well defined and what proportion of staff in that role can articulate that they in fact own the process

0-24 points in 6 point increments for electronic access to outpatient pharmacy information, access to outpatient medications, access to discharge medication orders from prior hospitalizations, and access to patient personal health records.

(can get up to 12 points if have facilitated paper access to these sources)

0-24 points in 6 point increments, depending on whether a standard medication form exists, to what extent patients use it, whether a system is in place to keep it updated, and whether the form is universally accessible

0-12 points in 4 point increments, depending on whether clinicians are trained to take a medication history, whether time is available to take an adequate history in $>80 \%$ of patients, and what portion of the staff have ever received feedback in their history taking

0-12 points in 4 point increments, depending on whether a standard script is available for discharge counseling, whether health literacy tools are used, and whether $>80 \%$ of staff is trained in discharge counseling, including patient centered communication

0-24 points available by calculating the product of the two below areas:

0-4 points available depending on whether there is a standard tool available to identify high risk patients and is used in $>80 \%$ of patients

0-6 points available depending on whether the too drives the intervention intensity, and $>80 \%$ of eligible patients receive the high-intensity intervention

0-24 points in 6 point increments depending on whether definition exists for standard and intense intervention, is embraced widely, staff are well trained, and are given adequate time to carry out the intensive bundle in high-risk patients

26 maximum points available based on electronic medication reconciliation tools having the following features: ability to compare various sources of preadmission medication information, access to medication adherence information, ability to document and verify a medication history, facilitation and verification of admission and discharge medication reconciliation, facilitation of admission and discharge order-writing, facilitation of patient/caregiver education, tools to facilitate communication with post-discharge providers, features to improve the reliability of the medication reconciliation process, and tools to identify high risk patients 
Table 1 Intervention components and scoring system (Continued)

\begin{tabular}{ll}
\hline Implementing components using & Sites implement medication reconciliation \\
phased approach & improvements in a phased manor using best practices \\
& for continuous quality improvement
\end{tabular}

Utilizing social marketing and engaging community resources

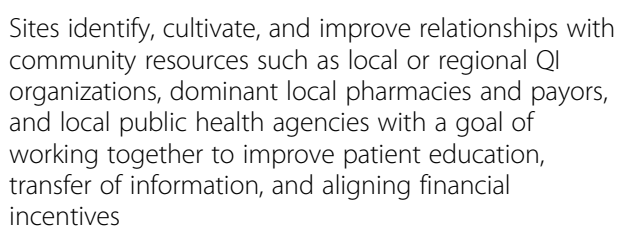

Sites identify, cultivate, and improve relationships with community resources such as local or regional Ql organizations, dominant local pharmacies and payors, and local public health agencies with a goal of working together to improve patient education, transfer of information, and aligning financial incentives

0-24 points in 6 point increments, depending on whether a plan exists to modify the intervention over time, to expand the intervention beyond the initial pilot sites, whether a time frame for expansion has been established and if the QI team has all the right personnel

0-24 points in 3 point increments, depending on usage of community resources and a patient safety advisory board in medication reconciliation, and usage of social marketing techniques with patients and providers
Board (IRB) approval was obtained from the Partners Healthcare System. In addition, each study site's IRB reviewed the study: four considered it an exempt QI project, while two sites required informed consent of patients prior to participation. Informed consent has been incorporated into the data collection process at these sites.

\section{Mentored local implementation}

MARQUIS utilizes SHM's mentored implementation approach [24], providing each site with a hospitalist mentor to facilitate toolkit implementation. Each mentor has QI expertise and performs distance mentoring through monthly calls with the study site's mentee/clinical champion, based upon the MARQUIS Implementation Guide which explains how to use the toolkit [25]. Each study site also receives two visits from the mentor, important from a QI standpoint (e.g., to maintain institutional support and enthusiasm among the local QI team, and better understand local practices) and from a research standpoint (e.g., to assess intervention fidelity and other barriers and facilitators of implementation). Additionally, SHM provides sites with an assigned lead project manager and research assistants located at SHM headquarters to assist with monitoring progress and collecting and analyzing

Table 2 Baseline characteristics of participating sites

\begin{tabular}{|c|c|c|c|c|c|c|}
\hline Site & 1 & 2 & 3 & 4 & 5 & 6 \\
\hline Hospital Type & $\begin{array}{l}\mathrm{AMC}^{1} / \\
\text { Community }\end{array}$ & Community & Community & AMC & AMC & VAMC $^{2}$ \\
\hline Region & Northeast & Southeast & Southeast & Midwest & West Coast & Midwest \\
\hline Setting & Urban & Suburban & Suburban & Urban & Urban & Rural \\
\hline Number of Beds & 653 & 110 & 535 & 600 & 450 & 45 \\
\hline Teaching Status & Teaching & Teaching & Non-teaching & Teaching & Teaching & Teaching \\
\hline Inpatient $\mathrm{CPOE}^{3}$ & Yes (Cerner) & $\begin{array}{l}\text { No (moving to } \\
\text { Cerner) }\end{array}$ & No & Yes (Epic) & No (moving to Epic) & Yes \\
\hline $\begin{array}{l}\text { Medication Reconciliation } \\
\text { Software }\end{array}$ & $\begin{array}{l}\text { Yes, integrated } \\
\text { with CPOE }\end{array}$ & $\begin{array}{l}\text { No (but yes with } \\
\text { Cerner) }\end{array}$ & Yes & $\begin{array}{l}\text { Yes, } \\
\text { integrated } \\
\text { with CPOE }\end{array}$ & $\begin{array}{l}\text { In progress (yes with } \\
\text { Epic/Apex) }\end{array}$ & $\begin{array}{l}\text { Yes, not fully } \\
\text { integrated }\end{array}$ \\
\hline $\begin{array}{l}\% \text { patients for whom site } \\
\text { has electronic access to } \\
\text { ambulatory medication } \\
\text { history }\end{array}$ & $50 \%$ & $0 \%$ & $<10 \%$ & $\sim 100 \%$ & $50 \%$ & $95 \%$ \\
\hline $\begin{array}{l}\text { Clinicians primarily } \\
\text { responsible for taking } \\
\text { medication histories }\end{array}$ & $\begin{array}{l}\text { Jointly shared by } \\
\text { physicians and } \\
\text { nurses }\end{array}$ & $\begin{array}{l}\text { Nurses first, then } \\
\text { physicians }\end{array}$ & $\begin{array}{l}\text { Pharmacy and } \\
\text { nursing }\end{array}$ & Nurses & Physicians & $\begin{array}{l}\text { Residents and } \\
\text { PAs }\end{array}$ \\
\hline $\begin{array}{l}\text { Process of medication } \\
\text { reconciliation at discharge }\end{array}$ & $\begin{array}{l}\text { Physicians use } \\
\text { electronic tool to } \\
\text { reconcile } \\
\text { medications }\end{array}$ & $\begin{array}{l}\text { Nurses fill out a } \\
\text { reconciliation form, } \\
\text { physicians reconcile } \\
\text { medications }\end{array}$ & $\begin{array}{l}\text { Physicians } \\
\text { reconcile } \\
\text { medications } \\
\text { using paper } \\
\text { form }\end{array}$ & $\begin{array}{l}\text { Physicians/ } \\
\text { NPs/ } \\
\text { PAs }^{4} \\
\text { reconcile } \\
\text { discharge } \\
\text { medications }\end{array}$ & $\begin{array}{l}\text { Physicians write orders, } \\
\text { pharmacists available by } \\
\text { request to reconcile } \\
\text { medications }\end{array}$ & $\begin{array}{l}\text { Physicians or } \\
\text { pharmacists, } \\
\text { depending on } \\
\text { time of day }\end{array}$ \\
\hline
\end{tabular}

1 Academic medical center.

2 Veterans Affairs medical center.

3 Computerized physician order entry.

4 Nurse practitioners/Physician assistants. 
data. Through the mentored implementation infrastructure, MARQUIS is affordable, adaptable, generalizable, scalable, and feasible for wide dissemination.

At each study site, a local QI team, led by the mentee/ clinical champion conducts monthly meetings to oversee intervention implementation and data collection, as well as to address protocol questions and determine the effectiveness of the interventions. Sites can access a central website with additional resources and a listserv. The monthly conference calls with their mentor and ad lib email communications promote a consistent approach across sites [16].

\section{Outcome assessment}

Study outcomes are assessed from 6 months preintervention through 21 months post-intervention (Table 3). The primary outcome is the number of potentially harmful unintentional medication discrepancies per patient, determined by a trained on-site pharmacist taking a "gold standard" medication history on a random sample of patients (20-25 per month). This history is then compared to the primary team's medication history and to admission and discharge orders. For discrepancies in admission or discharge orders not caused by history errors, the pharmacist reviews the medical record for a clinical explanation, and if necessary, talks with the medical team. This allows sites to distinguish unintentional medication discrepancies (i.e., due to reconciliation errors) from intentional medication changes. Physician adjudicators, blinded to the status of intervention implementation, record and categorize unintentional medication discrepancies with respect to: 1) timing (admission vs. discharge); 2) type (omission, additional medication, change in dose, route, frequency, or formulation, or other); 3) reason (history vs. reconciliation error); 4) potential for harm; and, 5) potential severity.

Secondary outcomes include accuracy and timeliness of the medical team's documented admission medication history, absence of discharge reconciliation errors, unplanned healthcare utilization (i.e., readmission or emergency department use), and patient satisfaction. Unplanned healthcare utilization to the same site within 30 days of discharge is determined from hospital records on all eligible patients. We examine patient satisfaction scores on the global satisfaction and the medication specific dimensions from the Hospital Consumer Assessment of Healthcare Providers and Systems (HCAHPS) survey, and will be aggregated by service, unit, and time period as data are available.

Contextual factors are measured using surveys of providers directly involved in the medication reconciliation process. Additionally, we measure intervention fidelity using direct observation during site visits, and evaluate training, support, and other steps offered to improve fidelity. Importantly, the extent of implementation is quantified as an intervention "score" for each toolkit component (Table 1) and factored into the analysis. The score is completed by the clinical champion at each site, informed by surveys administered to front-line clinicians who are directly involved in the medication reconciliation process when necessary.

\section{Data quality assurance}

In an effort to ensure consistency of on-site pharmacist data collection, the research team: 1) conducts monthly phone meetings with on-site pharmacists in which a patient case is reviewed for consistency and all discrepancies discussed; 2) provides on-site pharmacists with an updated 'frequently asked questions' (FAQ) document

\section{Table 3 Primary and secondary patient outcomes}

\begin{tabular}{|c|c|}
\hline Outcome & Description \\
\hline \multicolumn{2}{|l|}{ Primary outcome } \\
\hline $\begin{array}{l}\text { Unintentional Medication Discrepancies in admission and discharge } \\
\text { orders with potential for patient harm }\end{array}$ & Number of discrepancies per patient with potential for harm \\
\hline \multicolumn{2}{|l|}{ Process measures } \\
\hline Accuracy of preadmission medication history & $\begin{array}{l}\text { Proportion with accurate medication histories; number of history errors per } \\
\text { patient with potential for harm }\end{array}$ \\
\hline Absence of discharge reconciliation errors & $\begin{array}{l}\text { Proportion with error-free discharge medication orders; number of discharge } \\
\text { reconciliation errors per patient }\end{array}$ \\
\hline $\begin{array}{l}\text { Preadmission medication history documented within } 24 \text { hours of } \\
\text { admission }\end{array}$ & $\begin{array}{l}\text { Proportion of cases with on-time preadmission medication history } \\
\text { documentation }\end{array}$ \\
\hline \multicolumn{2}{|l|}{ Other outcome measures } \\
\hline $\begin{array}{l}\text { Emergency Department visit or readmission to index hospital within } \\
30 \text { days of discharge }\end{array}$ & Proportion of patients with ED visit or readmission \\
\hline Patient Satisfaction on HCAHPS ${ }^{1}$ survey & $\begin{array}{l}\text { Global satisfaction score; medication specific score; proportion who responded } \\
\text { "usually or always" to medication questions }\end{array}$ \\
\hline
\end{tabular}

${ }^{1}$ Hospital Consumer Assessment of Healthcare Providers and Systems. 
for managing new situations; and, 3) conducts site visits with the research team's pharmacist to observe data collection processes and provide feedback, including how to improve process efficiency.

To ensure the consistency of the adjudication process, the principal investigator (PI) conducts a quarterly conference call with the sites' physician adjudicators to discuss cases. In addition, the PI and a co-investigator review 6 cases from each site quarterly and review the results individually with each site's adjudicators. A FAQ document for adjudicators is updated and redistributed as needed.

\section{Web-based data center}

The study sites utilize a web-based data collection and reporting system built specifically for this study. The system creates HIPAA-compliant de-identified data sets for the coordinating data center and all investigators. The system allows for identification, classification, and adjudication of all discrepancies. Unintentional discrepancies identified by the on-site pharmacist are flagged in the system for physician adjudication. The data center provides detailed reports to trend discrepancies, facilitates uploads of patient-specific administrative data, tracks implementation of intervention components, and provides tools to support mentored implementation. It also provides tracking for patient enrollment compared to monthly targets.

\section{Statistical analysis}

The primary outcome will be analyzed using multivariable Poisson regression, including random effects and clustering of patients by site and treating physician. To account for temporal trends and the varied introduction of interventions by site, we will employ an interrupted time series analysis on all 3,600 patients across the 6 sites, evaluating outcomes monthly for 6 months preintervention and 21 months post-implementation [26]. The outcome is assessed as both a change from sitespecific baseline temporal trends (i.e., change in slope) and sudden improvement with implementation of the intervention components (i.e., change in y-intercept). If each site has concurrent controls, these can be entered into the model to partially adjust for the effect of concurrent interventions. The model also allows for the detection of iterative refinement of the intervention (i.e., continuous improvement over time), as well as ceiling effects (i.e., lack of continued improvement beyond a certain threshold).

We will assess implementation of each component of the toolkit monthly, using the scoring system on a scale of no adoption to complete adoption for each component (Table 1). Because many of the sites have already implemented pieces of the interventions, their scores often do not start at zero, and scores increase with the implementation of interventions to a maximum score of 318. The scores for each component will be entered into the multivariable model as time-varying covariates, such that we can determine whether implementation of a particular component is correlated with improved outcomes thereafter. This allows us to make inferences about the most important components of the intervention.

\section{Power and sample size}

For a stable estimate of temporal trends, each site's data collection goal is approximately 22 patients per month, beginning 6 months pre-intervention through 21 months post-intervention. Due to our study design it is impossible to know a priori the nature of our postintervention data, and therefore what our actual power would be to look at the effect of any specific intervention. However, based on prior research, we assumed that the number of medication discrepancies would follow a Poisson distribution and that, in the absence of an intervention, each hospitalized patient would have an average of 1.5 potentially harmful medication discrepancies in admission and discharge orders combined [27]. We also conservatively assumed that an intervention would be implemented at only 1 of 6 sites with 12 , not 21, months of follow-up due to delays in planning and phasing in the intervention widely. This would yield data from 133 patients pre-intervention and 266 patients postintervention. With these estimates and alpha $=0.05$, we would have $90 \%$ power to detect a reduction in the mean number of medication discrepancies from 1.5 per patient to 1.1 per patient [27].

As sites began to implement the intervention, one methodological issue that arose was the extent to which sites should over-sample data from hospital areas receiving early versions of the intervention. We decided on a 3:1 ratio of intervention to control patients during the intervention period. This allows for concurrent controls during the spread of the intervention, while maintaining an adequate sample of intervention patients to evaluate effects on patients outcomes.

\section{Program evaluation}

We will evaluate the influence of contextual factors, intervention fidelity, and intervening variables on implementation and outcomes using a mixed methods approach (Table 4). Measures of context are gathered using front-line staff and site surveys, direct observation, focus groups and interviews. At baseline, each site completed a site leader survey and front-line staff surveys to provide a semi-quantitative measurement of these issues. After the start of intervention implementation, a qualitative researcher conducts on-site focus groups with frontline staff and the QI team and interviews hospital leadership. At 12 months post-intervention, follow-up 
Table 4 Program evaluation

\begin{tabular}{|c|c|c|c|c|c|}
\hline Outcome & Timing & Data sources & Time required & $\begin{array}{l}\text { Data collection } \\
\text { process }\end{array}$ & $\begin{array}{l}\text { Form of analytic } \\
\text { variable }\end{array}$ \\
\hline \multicolumn{6}{|l|}{ Intervention assessment } \\
\hline $\begin{array}{l}\text { Medication Reconciliation } \\
\text { Intervention Score }\end{array}$ & $\begin{array}{l}\text { Monthly throughout } \\
\text { the intervention }\end{array}$ & $\begin{array}{l}\text { Surveys to site leaders at each } \\
\text { site, confirmed by mentor }\end{array}$ & $\begin{array}{l}1 \text { hour for baseline } \\
\text { assessment, } \\
15-20 \text { minutes for } \\
\text { subsequent } \\
\text { assessments }\end{array}$ & $\begin{array}{l}\text { Survey completed } \\
\text { in QuesGen }\end{array}$ & $\begin{array}{l}0-24 \text { scale for each } \\
\text { facet of medication } \\
\text { reconciliation; total } \\
\text { score }\end{array}$ \\
\hline $\begin{array}{l}\text { Front-line staff Surveys to } \\
\text { inform medication } \\
\text { reconciliation intervention } \\
\text { score }\end{array}$ & $\begin{array}{l}\text { As needed } \\
\text { throughout the study } \\
\text { period as } \\
\text { interventions } \\
\text { implemented likely to } \\
\text { affect results }\end{array}$ & $\begin{array}{l}\text { Surveys completed by } \\
\text { stakeholders (separate survey } \\
\text { for outpatient clinicians) }\end{array}$ & $\begin{array}{l}10 \text { minutes per } \\
\text { survey }\end{array}$ & $\begin{array}{l}\text { Survey } \\
\text { administered to all } \\
\text { potential } \\
\text { stakeholders using } \\
\text { on-line survey } \\
\text { software }\end{array}$ & $\begin{array}{l}\text { Results used } \\
\text { descriptively and to } \\
\text { inform Medication } \\
\text { Reconciliation } \\
\text { intervention score }\end{array}$ \\
\hline \multicolumn{6}{|l|}{ Measures of context } \\
\hline $\begin{array}{l}\text { Macro- and Micro- } \\
\text { organizational structure }\end{array}$ & Prior to intervention & $\begin{array}{l}\text { Modification of RAND ICICE } \\
\text { organizational survey [29] } \\
\text { completed by site leaders with } \\
\text { help from administrative/ } \\
\text { financial personnel }\end{array}$ & 1 hour per site & $\begin{array}{l}\text { Survey emailed to } \\
\text { respondents }\end{array}$ & $\begin{array}{l}\text { Varies by question } \\
\text { type }\end{array}$ \\
\hline $\begin{array}{l}\text { Safety culture, work climate, } \\
\text { and teamwork }\end{array}$ & Prior to intervention & $\begin{array}{l}\text { Modification of AHRQ patient } \\
\text { safety culture survey [30] } \\
\text { completed by stakeholders (e. } \\
\text { g., pharmacists, nurses, } \\
\text { physicians) }\end{array}$ & $\begin{array}{l}10 \text { minutes per } \\
\text { survey }\end{array}$ & $\begin{array}{l}\text { Survey } \\
\text { administered to all } \\
\text { potential } \\
\text { stakeholders using } \\
\text { on-line survey } \\
\text { software }\end{array}$ & $\begin{array}{l}\text { Composite } \\
\text { frequency of } \\
\text { positive responses } \\
\text { in each of } 10 \\
\text { dimensions of } \\
\text { safety }\end{array}$ \\
\hline $\begin{array}{l}\text { Satisfaction with medication } \\
\text { reconciliation process and } \\
\text { software, perceptions of } \\
\text { errors related to medication } \\
\text { reconciliation }\end{array}$ & $\begin{array}{l}\text { Prior to intervention, } \\
\text { again post- } \\
\text { intervention }\end{array}$ & $\begin{array}{l}\text { Survey completed by } \\
\text { stakeholders }\end{array}$ & $\begin{array}{l}5 \text { minutes per } \\
\text { survey }\end{array}$ & $\begin{array}{l}\text { As with safety } \\
\text { culture }\end{array}$ & $\begin{array}{l}\text { Frequency of } \\
\text { positive responses }\end{array}$ \\
\hline Job satisfaction and burnout & $\begin{array}{l}\text { Prior to intervention, } \\
\text { again post- } \\
\text { intervention }\end{array}$ & Surveys [31,32] & $\begin{array}{l}5 \text { minutes per } \\
\text { survey }\end{array}$ & $\begin{array}{l}\text { As with safety } \\
\text { culture }\end{array}$ & $\begin{array}{l}\text { Frequency of } \\
\text { positive responses }\end{array}$ \\
\hline \multicolumn{6}{|l|}{ Qualitative information } \\
\hline Focus Groups & At first site visit & $\begin{array}{l}5 \text { focus groups of } 6-8 \\
\text { representative stakeholders } \\
\text { each, grouped by type, } 35 \\
\text { total per site }\end{array}$ & $60-90$ minutes & $\begin{array}{l}\text { Administered by } \\
\text { qualitative } \\
\text { researcher }\end{array}$ & \\
\hline Individual Interviews & $\begin{array}{l}\text { Follow-up phone calls } \\
\text { one year after focus } \\
\text { groups }\end{array}$ & $\begin{array}{l}\text { One-on-one interviews with } \\
\text { champions and } 2-3 \text { key } \\
\text { opinion leaders per site }\end{array}$ & 30-45 minutes & $\begin{array}{l}\text { Administered by } \\
\text { phone by } \\
\text { qualitative } \\
\text { researcher }\end{array}$ & \\
\hline \multicolumn{6}{|l|}{ Intervention fidelity } \\
\hline Intervention Fidelity & At each site visit & $\begin{array}{l}\text { Direct observation of } \\
\text { medication reconciliation } \\
\text { process }\end{array}$ & $\begin{array}{l}6 \text { hours at each } \\
\text { visit (over two } \\
\text { days) }\end{array}$ & Mentor & $\begin{array}{l}\text { Mean percent } \\
\text { completion of each } \\
\text { process component; } \\
\text { process fidelity } \\
\text { scale }(1-4)\end{array}$ \\
\hline
\end{tabular}

interviews are conducted by telephone. For focus groups and interviews, a convenience sample of staff is selected by role and department to ensure broad representation [28].

Intervention fidelity is assessed by direct, semistructured observation of the site's medication reconciliation process by their mentor during site visits at 3 and 12 months after implementation of the intervention.
The observation protocol evaluates five steps of the medication reconciliation process: taking an admission medication history, identifying high risk patients to receive a high intensity medication reconciliation intervention, performing discharge medication reconciliation, performing discharge medication counseling using the teach back method, and forwarding the discharge medication list to the next provider of care after discharge. 
The mentor observes the actual process to identify if the intervention is being implemented as designed (content fidelity) and rates how well it was performed on a 1 to 4 scale (process fidelity) [33]. The observation forms also allow documentation of systems issues that impact the medication reconciliation process based on the Systems Engineering Initiative for Patient Safety (SEIPS) model's [34] 5 domains: people, technology/tools, tasks, organization, and environment. Mentors received group training on how to assess fidelity, using a coding manual with standardized examples and training from a human factors expert. Mentors share feedback about the direct observations during the site visit with the site leader and QI team.

Intervening variables (i.e., in determining intervention fidelity) are assessed from surveys of front-line staff preand post-intervention. Topics include the quality of education and training received in the intervention (e.g., in taking medication histories), degree of input into intervention design, and adequacy of staffing and time to complete medication reconciliation processes. Other barriers and facilitators of intervention implementation are determined from structured and open-ended questions regarding the front-line staff's opinions of the medication reconciliation process and its perceived impact on patient care.

\section{Study timeline}

Figure 2 outlines the timeline of the study. The study's three critical time points are: intervention start, interim evaluation with iterative refinement of the intervention and a second draft of the implementation guide 9 months after the start, and end of the intervention after 21 months.

\section{Discussion}

Baseline data collection began March 2011 and was completed August 2012. Over 1,000 patients have been enrolled to date across the 6 sites, of which 980 have data entered in a centralized database (Table 5). Of these, preliminary analyses show 844 patients have had discrepancies adjudicated for potential harm. The total number of unintentional medication discrepancies in admission and discharge orders per patient varies by site from 2.35 to 4.67 (mean $=3.35)$. Consistent with prior research, most discrepancies are due to history errors (mean 2.12 per patient) as opposed to reconciliation errors (mean 1.23 per patient) [14]. The number of potentially harmful medication discrepancies averages 0.45 per patient and varies by site from 0.13 to 0.82 per patient. In comparison, in prior studies by Schnipper et al. potentially harmful medication discrepancies began at 1.44 per patient, then decreased to 1.05 and then 0.32 per

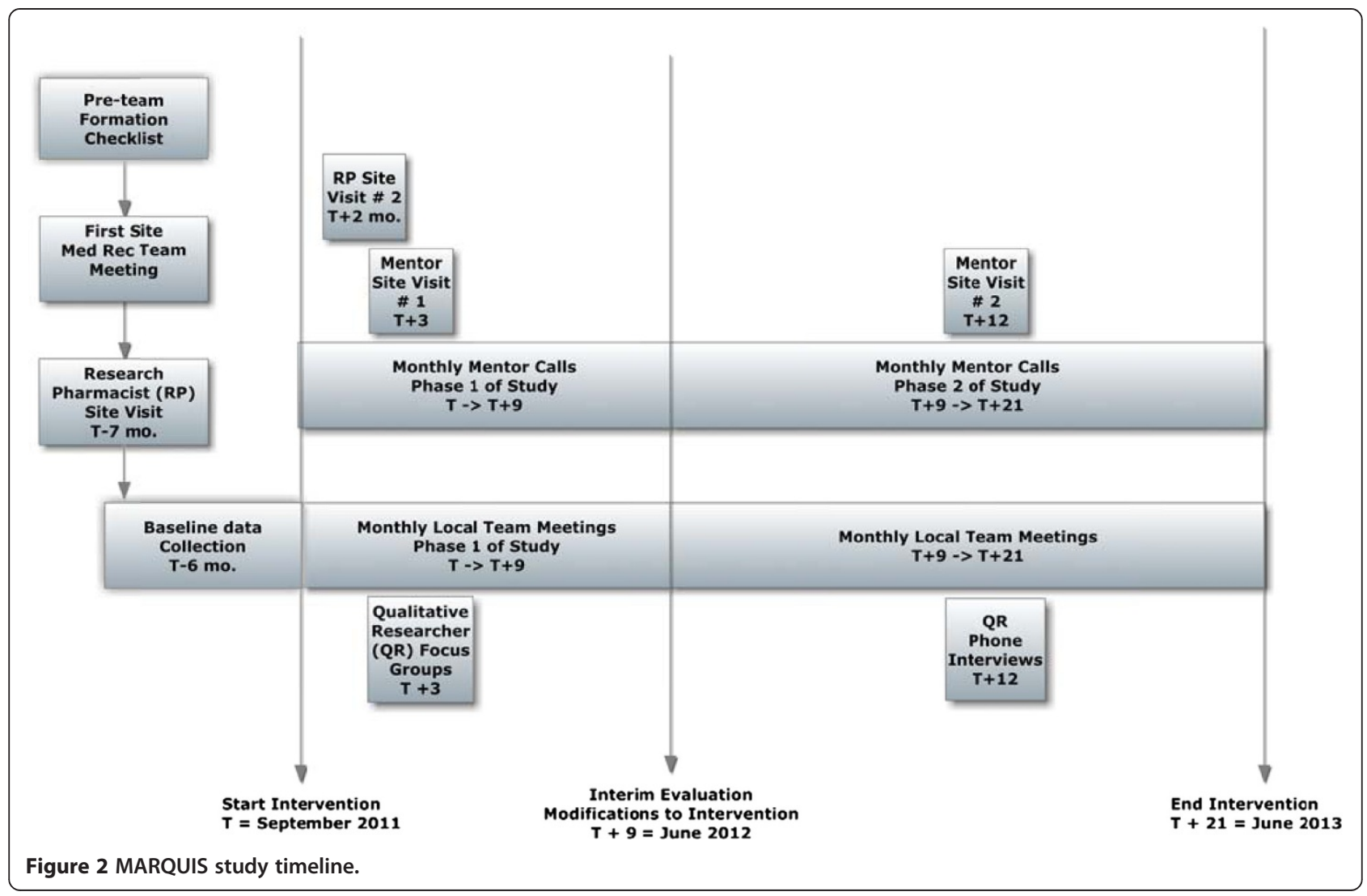


Table 5 Baseline results

\begin{tabular}{|c|c|c|c|c|c|c|c|}
\hline & $\begin{array}{l}\text { All sites } \\
(\mathrm{N}=927)\end{array}$ & $\begin{array}{l}A \\
(n=313)\end{array}$ & $\begin{array}{l}\text { B } \\
(n=360)\end{array}$ & $\begin{array}{l}C \\
(n=124)\end{array}$ & $\begin{array}{l}D \\
(n=150)\end{array}$ & $\begin{array}{l}E \\
(n=82)\end{array}$ & $\begin{array}{l}F \\
(n=22)\end{array}$ \\
\hline $\begin{array}{l}\text { Total discrepancies per patient (history and reconciliation): admission and } \\
\text { discharge }\end{array}$ & 3.77 & 4.52 & 2.43 & 2.91 & 3.27 & 3.16 & 1.73 \\
\hline Total discrepancies at admission & 1.72 & 2.16 & 1.11 & 1.02 & 1.49 & 1.35 & 0.73 \\
\hline Total discrepancies at discharge & 2.05 & 2.36 & 1.33 & 1.89 & 1.79 & 1.80 & 1.00 \\
\hline History discrepancies: admission and discharge & 2.39 & 3.36 & 1.98 & 1.91 & 0.66 & 0.87 & 2.59 \\
\hline History discrepancies: admission & 0.97 & 1.34 & 0.88 & 0.44 & 0.27 & 0.65 & 1.91 \\
\hline History discrepancies: discharge & 1.41 & 2.02 & 1.10 & 1.47 & 0.39 & 0.22 & 0.68 \\
\hline Reconciliation discrepancies: admission and discharge & 1.38 & 1.16 & 0.44 & 1.00 & 2.61 & 2.29 & 2.59 \\
\hline Reconciliation discrepancies: admission & 0.75 & 0.82 & 0.22 & 0.58 & 1.22 & 0.71 & 1.91 \\
\hline Reconciliation discrepancies: discharge & 0.64 & 0.35 & 0.23 & 0.42 & 1.39 & 1.59 & 0.68 \\
\hline \multicolumn{8}{|l|}{ Adjudicated results } \\
\hline Number of potentially harmful discrepancies per patient ${ }^{1}:$ total & 0.46 & 0.26 & 0.45 & 0.67 & 0.70 & 0.82 & 0.36 \\
\hline Potentially harmful discrepancies: admission & 0.16 & 0.12 & 0.17 & 0.17 & 0.15 & 0.29 & 0.09 \\
\hline Potentially harmful discrepancies: discharge & 0.30 & 0.14 & 0.28 & 0.50 & 0.55 & 0.53 & 0.27 \\
\hline Potential severity: admission & 0.12 & 0.10 & 0.12 & 0.14 & 0.13 & 0.23 & 0.00 \\
\hline \multicolumn{8}{|l|}{ Significant } \\
\hline Serious $^{2}$ & 0.04 & 0.03 & 0.05 & 0.03 & 0.03 & 0.06 & 0.09 \\
\hline Potential severity: discharge & 0.23 & 0.13 & 0.21 & 0.44 & 0.40 & 0.32 & 0.18 \\
\hline \multicolumn{8}{|l|}{ Significant } \\
\hline Serious $^{2}$ & 0.07 & 0.01 & 0.07 & 0.06 & 0.15 & 0.21 & 0.09 \\
\hline
\end{tabular}

${ }^{1}$ Greater than $50 \%$ chance that the medication discrepancy identified had potential to harm patient

2 There were no life-threatening discrepancies.

patient with successive versions of medication reconciliation interventions $[27,35]$.

Challenges have arisen during the initial implementation. From a research perspective, these included delays in signing data use agreements, IRB requirement for patient consent at some sites, delays in obtaining IRB approval, and staffing challenges, all of which led to delays in completing baseline data collection. Another challenge was achieving adequate response rates from frontline surveys. In the end, we asked each site to identify a select group of clinicians likely to complete surveys while still representative of the locations and provider types involved in the medication reconciliation process, sacrificing some generalizability for better rates (and thus internal validity). Operationally, rather than create a distinct "version 2" of the intervention, we chose to iteratively refine and add to our toolkit as sites and mentors have identified specific needs, although we do plan to develop a distinct "second edition" of the implementation guide.

To date, initial site visits have been conducted at 3 of the 6 sites within 4 months of start of the intervention implementation. Feedback after mentor and qualitative researcher visits were shown to be more valuable at sites that were further along with intervention implementation.
This timing allowed for more feedback on barriers and facilitators to implementation from focus group participants intimately involved in the intervention, and allowed for richer data collection on intervention fidelity, creating more detailed feedback to sites on how to improve their interventions going forward. On the other hand, because site visits also enhanced the visibility and institutional support of the project at the sites, for those sites that were struggling with implementation, the decision was made to conduct these visits on time anyway, trading some data loss regarding intervention fidelity for gains in local support.

MARQUIS seeks to improve medication safety at participating hospitals, while rigorously studying the implementation of a best practices toolkit and contextual factors that may influence outcomes. As such, the study offers one approach to conducting rigorous, "real world" QI research in which we hope to understand: 1) the most important components of the intervention; 2) reasons for success or failure; and, 3) barriers and facilitators of implementation. MARQUIS also attempts to balance the criticism for a more case-based approach to QI research with more rigorous outcome assessment that adequately adjusts for potential confounders. 
Importantly, MARQUIS does not provide sites with resources for the intervention and only a small stipend for data collection, similar to QI efforts at most hospitals. This lowered the cost of the study and also makes it more generalizable since other sites wishing to adopt the intervention toolkit most likely would not receive external resources for implementation. Nevertheless, this also makes sites more vulnerable to resource constraints and changes in leadership or institutional priorities, in particular during the lag time between applying for funding and beginning the intervention. As hospitals are increasingly challenged to conserve resources, projects like MARQUIS are more likely to succeed if medication safety is a consistent priority or if a favorable return on investment is anticipated. To address the latter, we have provided sites with business plans on making the business case for medication reconciliation, which is available online in the MARQUIS implementation guide.

Other challenges reflect the need to balance the needs of QI work with research, such as the length of preintervention data collection (shorter for QI, longer for research) and the optimal timing of site visits (earlier for QI to enlist institutional support, later for research to best assess intervention fidelity).

Despite these challenges, our use of a mentored implementation model makes MARQUIS a generalizable approach to studying the improvement of complex processes like inpatient medication reconciliation. If the intervention is shown to be successful, mentored implementation resources could easily be scaled up. Using a refined version of the tools and implementation lessons, MARQUIS holds promise to provide a large impact on medication safety during transitions in care across many hospitals.

\footnotetext{
Abbreviations

ADEs: Adverse drug events; AHRQ: Agency for healthcare research and quality; AMC: Academic medical center; APNs: Advanced practice nurses; CPOE: Computerized physician order entry; FAQ: Frequently asked questions; HCAHPS: Hospital consumer assessment of healthcare providers and systems; IRB: Institutional review board; MARQUIS: Multicenter medication reconciliation quality improvement study; NPs/PAs: Nurse practitioners/ Physician assistants; Pl: Primary investigator; Ql: Quality improvement; SHM: Society of hospital medicine; TJC: The joint commission; VAMC: Veterans affairs medical center.
}

\section{Competing interests}

Dr. Kripalani is a consultant to and holds equity in PictureRx, LLC. The terms of this agreement were reviewed and approved by Vanderbilt University in accordance with its conflict of interest policies. Dr. Schnipper is a consultant to QuantiaMD, for whom he helps create educational tools for providers and patients regarding medication safety; these tools are not part of MARQUIS. Dr. Schnipper is also principal investigator of an investigator-initiated study of interventions to improve transitions in care in patients with Diabetes. The terms of these agreements were reviewed and approved by Partners HealthCare and Harvard Medical School in accordance with its conflict of interest policies. All other authors have no competing interests.

\section{Authors' contributions}

JLS, SK, TBW, JS, and PJK designed the study. EE, DJC, DH, JLG, and MWW are members of the advisory board and provided input throughout the study to assist in refining the process. AHS and JLS drafted the manuscript. All authors read, made significant contributions, and approved the final manuscript.

\section{Acknowledgements}

Jacquelyn A. Minahan, Nyryan V. Nolido, Sabrina P. Wong; Steering committee members.

\section{Funding}

Grant support: Agency for Healthcare Research and Quality (AHRQ) R18HS019598-01 to the Society of Hospital Medicine (SHM) with Dr. Schnipper as principle investigator.

\section{Author details}

${ }^{1}$ Geriatric Research, Education and Clinical Center, VA Tennessee Valley Healthcare System, Nashville, TN, USA. ${ }^{2}$ Section of Hospital Medicine, Division of General Internal Medicine and Public Health, Department of Medicine, Vanderbilt University, Nashville, TN, USA. ${ }^{3}$ Center for Hospital Innovation and Improvement, Society of Hospital Medicine, Philadelphia, PA, USA. ${ }^{4}$ Division of General Medicine, Brigham and Women's Hospital and Harvard Medical School, Boston, MA, USA. ${ }^{5}$ Center for Quality and Productivity Improvement, UW Madison; Department of Medicine, University of Wisconsin School of Medicine and Public Health, Madison, Wisconsin, USA. ${ }^{6}$ Peabody College, Vanderbilt University, Nashville, TN, USA. ${ }^{7}$ Department of Medicine Quality Program, Emory University, Atlanta, GA, USA. ${ }^{8}$ The Center for Comprehensive Access and Delivery Research and Evaluation (CADRE) at the lowa City VA Healthcare System, University of lowa Carver College of Medicine, lowa City, IA, USA. 'Department of Pharmacy Services, Brigham and Women's Hospital, Boston, MA, USA. ${ }^{10}$ Sunnybrook Health Sciences Centre, University of Toronto, Toronto, Canada. ${ }^{11}$ American Society of Health-System Pharmacists Research and Education Foundation, Bethesda, MD, USA. ${ }^{12}$ American Association of Critical Care Nurses, Aliso Viejo, CA, USA. ${ }^{13}$ Inpatient Clinician Educator Service, Massachusetts General Hospital; Harvard Medical School, Boston, MA, USA. ${ }^{14}$ Division of Hospital Medicine, Northwestern University Feinberg School of Medicine, Chicago, IL, USA. ${ }^{15}$ BWH Hospitalist Service, Division of General Medicine, Brigham and Women's Hospital; Harvard Medical School, Boston, MA, USA.

Received: 19 March 2013 Accepted: 18 June 2013 Published: 25 June 2013

\section{References}

1. Coleman EA, Smith JD, Raha D, Min SJ: Posthospital medication discrepancies: prevalence and contributing factors. Arch Intern Med 2005, 165:1842-1847.

2. Smith JD, Coleman EA, Min SJ: A new tool for identifying discrepancies in postacute medications for community-dwelling older adults. Am J Geriatr Pharmacother 2004, 2:141-147.

3. Cornish PL, Knowles SR, Marchesano R, Tam V, Shadowitz S, Juurlink DN, Etchells EE: Unintended medication discrepancies at the time of hospital admission. Arch Intern Med 2005, 165:424-429.

4. Schnipper JL, Kirwin JL, Cotugno MC, Wahlstrom SA, Brown BA, Tarvin E, Kachalia A, Horng M, Roy CL, McKean SC, Bates DW: Role of pharmacist counseling in preventing adverse drug events after hospitalization. Arch Intern Med 2006, 166:565-571.

5. Tam VC, Knowles SR, Cornish PL, Fine N, Marchesano R, Etchells EE: Frequency, type and clinical importance of medication history errors at admission to hospital: a systematic review. CMAJ Canadian Medical Association Journal 2005, 173:510-515.

6. Climente-Marti M, Garcia-Manon ER, Artero-Mora A, Jimenez-Torres NV: Potential risk of medication discrepancies and reconciliation errors at admission and discharge from an inpatient medical service. Ann Pharmacother 2010, 44:1747-1754.

7. Chan AH, Garratt E, Lawrence B, Turnbull N, Pratapsingh P, Black PN: Effect of education on the recording of medicines on admission to hospital. J Gen Intern Med 2010, 25:537-542.

8. Medication reconciliation review. http://www.ihi.org/knowledge/Pages/Tools/ MedicationReconciliationReview.aspx. 
9. Shekelle PG, Pronovost PJ, Wachter RM, McDonald KM, Schoelles K, Dy SM, Shojania K, Reston JT, Adams AS, Angood PB, et al: The Top patient safety strategies that Can Be encouraged for adoption Now. Ann Intern Med 2013, 158:365-368.

10. Van Houtven $\mathrm{CH}$, Jeffreys AS, Coffman CJ: Home health care and patterns of subsequent VA and medicare health care utilization for veterans. Gerontologist 2008, 48:668-678.

11. WHO Collaborating Centre for Patient Safety Solutions: Assuring medication accuracy at transitions in care. In Book Assuring medication accuracy at transitions in care. vol. 1st edition. City: World Health Organization; 2007

12. Mueller SK, Sponsler KC, Kripalani S, Schnipper JL: Hospital-based medication reconciliation practices: a systematic review. Arch Intern Med 2012, 172:1057-1069.

13. Koehler BE, Richter KM, Youngblood L, Cohen BA, Prengler ID, Cheng D, Masica AL: Reduction of 30-day postdischarge hospital readmission or emergency department (ED) visit rates in high-risk elderly medical patients through delivery of a targeted care bundle. J Hosp Med 2009, 4:211-218.

14. Pippins JR, Gandhi TK, Hamann C, Ndumele CD, Labonville SA, Diedrichsen EK, Carty MG, Karson AS, Bhan I, Coley CM, et al: Classifying and predicting errors of inpatient medication reconciliation. J Gen Intern Med 2008, 23:1414-1422

15. Kaboli PJ, Fernandes O: Medication reconciliation: moving forward. Arch Intern Med 2012, 172:1069-1070.

16. Greenwald JL, Halasyamani L, Greene J, LaCivita C, Stucky E, Benjamin B, Reid W, Griffin FA, Vaida AJ, Williams MV: Making inpatient medication reconciliation patient centered, clinically relevant and implementable: a consensus statement on key principles and necessary first steps. J Hosp Med 2010, 5:477-485.

17. Brown C, Hofer T, Johal A, Thomson R, Nicholl J, Franklin BD, Lilford RJ: An epistemology of patient safety research: a framework for study design and interpretation. Part 1. Conceptualising and developing interventions. Qual Saf Health Care 2008, 17:158-162.

18. Brown C, Hofer T, Johal A, Thomson R, Nicholl J, Franklin BD, Lilford RJ: An epistemology of patient safety research: a framework for study design and interpretation. Part 2. Study design. Qual Saf Health Care 2008, 17:163-169.

19. Brown C, Hofer T, Johal A, Thomson R, Nicholl J, Franklin BD, Lilford RJ: An epistemology of patient safety research: a framework for study design and interpretation. Part 3. End points and measurement. Qual Saf Health Care 2008, 17:170-177.

20. Brown C, Hofer T, Johal A, Thomson R, Nicholl J, Franklin BD, Lilford RJ: An epistemology of patient safety research: a framework for study design and interpretation. Part 4. One size does not fit all. Qual Saf Health Care 2008, 17:178-181.

21. Donabedian A: Explorations in quality assessment and monitoring. In The definition of quality and approaches to it assessment. Edited by Griffith JR. Washington, DC: Health Administration Press; 1980:4-163.

22. Mueller SK, Kripalani S, Stein J, Kaboli P, Wetterneck TB, Salanitro AH, Labonville S, Etchells E, Hanson D, Williams MV, et al: Development of a toolkit to disseminate best practices in inpatient medication reconciliation. JtComm J Qual Patient Saf 2013. In press.

23. Hawe P, Shiell A, Riley T: Complex interventions: how "out of control" can a randomised controlled trial be? BMJ 2004, 328:1561-1563.

24. Maynard GA, Budnitz TL, Nickel WK, Greenwald JL, Kerr KM, Miller JA, Resnic JN, Rogers KM, Schnipper JL, Stein JM, et al: 2011 John M. Eisenberg patient safety and quality awards. Mentored implementation: building leaders and achieving results through a collaborative improvement model. Innovation in patient safety and quality at the national level. Jt Comm J Qual Patient Saf 2012, 38:301-310.

25. Schnipper JL, Schnipper JL: MARQUIS implementation manual: a guide for medication reconciliation quality improvement. In Book MARQUIS implementation manual: a guide for medication reconciliation quality improvement. City: Society of Hospital Medicine; 2011.

26. McDowall D, McCleary R, Meidinger EE, Hay RA: Interrupted time series analysis. Thousand Oaks: SAGE; 1980.

27. Schnipper UL, Hamann C, Ndumele CD, Liang CL, Carty MG, Karson AS, Bhan I, Coley CM, Poon E, Turchin A, et al: Effect of an electronic medication reconciliation application and process redesign on potential adverse drug events: a cluster-randomized trial. Arch Intern Med 2009, 169:771-780.
28. Kuper A, Lingard L, Levinson W: Critically appraising qualitative research. BMJ 2008, 337:a1035.

29. RAND: ICICE organization characteristics survey for ICICE contact. Santa Monica, CA; 1999

30. Agency for Healthcare Research and Quality: Hospital survey on patient safety culture. http://www.ahrq.gov/professionals/quality-patient-safety/ patientsafetyculture/hospital/index.html. Accessed January 10, 2010.

31. Quinn R, Seashore S, Kahn R, Mangion T, Cambell D, Staines G, McCullough M: Survey of working conditions: final report on univariate and bivariate tables. In Book survey of working conditions: final report on univariate and bivariate tables. City: Government Printing Office; 1971.

32. Wetterneck TB, Linzer M, McMurray JE, Douglas J, Schwartz MD, Bigby J, Gerrity MS, Pathman DE, Karlson D, Rhodes E: Worklife and satisfaction of general internists. Arch Intern Med 2002, 162:649-656.

33. Dumas JE, Lynch AM, Laughlin JE, Phillips Smith E, Prinz RJ: Promoting intervention fidelity. Conceptual issues, methods, and preliminary results from the EARLY ALLIANCE prevention trial. Am J Prev Med 2001, 20:38-47.

34. Carayon P, Hundt AS, Alvarado CJ, Springman SR, Ayoub P: Patient safety in outpatient surgery: the viewpoint of the healthcare providers. Ergonomics 2006, 49:470-485

35. Schnipper J: Assessment of improvements to IT-based medication reconciliation. In Book Assessment of improvements to IT-based medication reconciliation. City: Society of Hospital Medicine; 2010

doi:10.1186/1472-6963-13-230

Cite this article as: Salanitro et al: Rationale and design of the Multicenter Medication Reconciliation Quality Improvement Study (MARQUIS). BMC Health Services Research 2013 13:230.

\section{Submit your next manuscript to BioMed Central and take full advantage of:}

- Convenient online submission

- Thorough peer review

- No space constraints or color figure charges

- Immediate publication on acceptance

- Inclusion in PubMed, CAS, Scopus and Google Scholar

- Research which is freely available for redistribution

Submit your manuscript at www.biomedcentral.com/submit
C BioMed Central 